\title{
Type I interferonopathies with novel compound heterozygous TREX1 mutations in two siblings with different symptoms responded to tofacitinib
}

Shiyu Zhang ${ }^{1 \dagger}$, Jiaxing Song ${ }^{2+}$, Yuyan Yang ${ }^{3}$, Huilei Miao ${ }^{3}$, Lu Yang ${ }^{1}$, Yuehua Liu' ${ }^{1}$ Xue Zhang ${ }^{2}$, Yaping Liu ${ }^{2^{*}}$ and Tao Wang ${ }^{1 *+}$ (D)

\begin{abstract}
Background: Type I interferonopathies are a group of rare autoimmune diseases characterised by excessive activation of type I interferon that leads to disturbances in immune function. Three prime repair exonuclease 1 (TREX1) is an important exonuclease and plays an important role in DNA damage repair. TREX1 mutations are associated with many type I interferonopathies. Studies have been published on the effectiveness of tofacitinib in the treatment of type I interferonopathies. The aim of this study is to identify the pathogenic variation in a Chinese family with type I interferonopathies and to observe the therapeutic effects of tofacitinib.
\end{abstract}

Methods: A Chinese family with two members with type I interferonopathies was investigated. Whole exome sequencing and Sanger sequencing were applied for mutation screening using peripheral blood DNA of the patient and her family members. Sequencing results were analysed using bioinformatics software tools including VarCards and PolyPhen-2. Close clinical follow-up and observation were used to record changes in the disease before and after treatment with tofacitinib.

Results: Compound heterozygous variants of TREX1 were observed in the patient's genome. One was a missense variant (NM_016381; c.C227T; p.Ala76Val) from the patient's father, and the other was a frameshift variant (NM_ 016381; c.458dupA; p.GIn153GInfs*3) from the patient's mother. One of the proband's elder brothers with similar skin lesions also carried these two variants. This brother of the proband had more serious cutaneous involvement with the comorbidity of cerebral palsy. These TREX1 variants have not been reported in previous studies and are predicted to be highly pathogenic. The proband was given tofacitinib that led to a marked improvement.

(Continued on next page)

\footnotetext{
* Correspondence: ypliu@ibms.pumc.edu.cn; wangtaopumch@126.com

${ }^{\dagger}$ Shiyu Zhang, Jiaxing Song, Yaping Liu and Tao Wang contributed equally to this work.

${ }^{2}$ Department of Medical Genetics and National Laboratory of Medical Molecular Biology, Institute of Basic Medical Sciences, Chinese Academy of Medical Sciences and Peking Union Medical College, Beijing 100005, China 'Department of Dermatology, Peking Union Medical College Hospital, Chinese Academy of Medical Sciences and Peking Union Medical College, Beijing 100730, China

Full list of author information is available at the end of the article
}

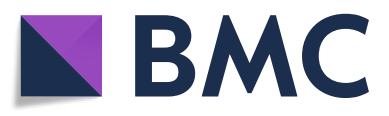

( The Author(s). 2021 Open Access This article is licensed under a Creative Commons Attribution 4.0 International License, which permits use, sharing, adaptation, distribution and reproduction in any medium or format, as long as you give appropriate credit to the original author(s) and the source, provide a link to the Creative Commons licence, and indicate if changes were made. The images or other third party material in this article are included in the article's Creative Commons licence, unless indicated otherwise in a credit line to the material. If material is not included in the article's Creative Commons licence and your intended use is not permitted by statutory regulation or exceeds the permitted use, you will need to obtain permission directly from the copyright holder. To view a copy of this licence, visit http://creativecommons.org/licenses/by/4.0/ The Creative Commons Public Domain Dedication waiver (http://creativecommons.org/publicdomain/zero/1.0/) applies to the data made available in this article, unless otherwise stated in a credit line to the data. 
(Continued from previous page)

Conclusions: We identified two novel complex heterozygous variants in the TREX1 gene, which may underlie the molecular pathogenesis of the type I interferonopathies observed in members of this family. Tofacitinib could be an alternative treatment for this disease.

Keywords: Aicardi-Goutières syndrome, Compound heterozygote, Familial chilblain lupus, Interferonopathy, Tofacitinib, TREX1

\section{Background}

Type I interferon (IFN) plays an important role in the immune defence against viral infections [1]. Excessive activation of type I IFN can lead to disturbances in immune function. Type I interferonopathies are autoinflammatory and autoimmune disorders $\left[\begin{array}{ll}1, & 2]\end{array}\right.$ characterised by the upregulation of type I IFN. Notwithstanding type I IFN upregulation, each disease in the category of type I interferonopathies has its own clinical manifestations. The main types of diseases and their causative genes are shown in Table $1[1,3]$.

Three prime repair exonuclease 1 (TREX1) plays an important role in DNA damage repair [1, 4]. A growing number of studies have shown that TREX1 mutations are associated with multiple type I interferonopathies [1, 5]. Aicardi-Goutières syndrome (AGS) is a subgroup of type I interferonopathies [1, 3, 6]. Familial chilblain lupus (FCL) is a subtype of AGS characterised by papular skin lesions, which occur as a result of the cold [1]. FCL affects the tip of the finger or toe and the folds of the nail, and there is usually no associated neurological condition $[1,7]$. The pathogenic genes of FCL include TREX1, SAMHD1 and STING. Tofacitinib, a Janus kinase (JAK) inhibitor, has been described to improve type I interferonopathies by suppressing the overactivated JAK / signal transducing activator of transcription (STAT) pathway.

In this article, we describe the clinical, pathological and genetic characteristics of two cases with complex heterozygous variants in the TREX1 gene. These two variants have not been reported in previous studies and have not been reported as a polymorphic change in public databases; the frequency of the variants in the population is extremely low. Tofacitinib treatment led to an improvement in the patient.

\section{Materials and methods Participants}

A 2-year-old female was admitted to our outpatient clinic in the Department of Dermatology due to painful bluish-red papular lesions of the skin in acral locations. The erythematous infiltrates first occurred when she was 8 months old, affecting mainly the interphalangeal joints of her fingers, toes and ears. Ulcerations were commonly noted in distal portions of her toes and fingers, causing nail changes. Scars were left without blisters or necrotic areas (Figs. 1a and 2a). Erythematous to violaceous indurated infiltrative plaques appeared on the face (Fig. 3a).

She is the 3rd child of a healthy non-consanguineous couple with no family history of haemophilia or skin diseases (Fig. 4a). Her eldest brother was in good health, while her elder brother presented similar skin lesions, albeit much more severe, at the same age, with necrotic destruction leading to the falling off of his fingers. In addition to the skin disorder, he also had cerebral-palsylike abnormality in motor development and posture.

A skin biopsy taken from the borders of an erythematous lesion upon her right foot showed significant hyperkeratosis and acanthosis. There was lymphocytedominated inflammatory infiltration at the dermal junction and around the dermal vessels and adnexa, and neovascularisation in the dermal papilla (Fig. 5).

Participants and patients in this study have given written informed consent to be in the study and to allow the publication of their case details. The ethics review board of the institution approved the study.

\section{DNA sample preparation}

Genomic DNA was extracted from peripheral blood using the QIAamp DNA Blood Mini Kit (QIAGEN, Hilden, Germany), according to the standard protocol, and quantified using a NanoDROP 2000 spectrophotometer (Thermo Scientific; Waltham, MA, USA).

\section{Mutational analysis of the TREX1 gene}

Whole exome sequencing (WES) was conducted in the proband by the Novogene company on the Illumina NovaSeq platform, with an average sequencing depth of 100X. Raw sequence results were aligned to the human reference genome (GRCh37/hg19) and annotated to obtain the candidate variants. Then the candidate variants were validated using Sanger sequencing to confirm the WES results. Primers were designed using Primer3web, version 4.1.0 for the suspected disease-causing genes. Variants were interpreted using VarCards (http://varcards.biols.ac.cn/) and PolyPhen2 (http://genetics.bwh. harvard.edu/pph2/). And we also used SWISS-MODEL 
Table 1 The main types of type I interferonopathies and their causative genes

\begin{tabular}{|c|c|}
\hline Disease & Gene \\
\hline Aicardi-Goutières syndrome (AGS) & $\begin{array}{l}\text { TREX1, RNASEH2A, RNASEH2B, } \\
\text { RNASEH2C, SAMHD1, ADAR1, IFIH1 }\end{array}$ \\
\hline Retinal vasculopathy with cerebral leukodystrophy & TREX1 \\
\hline Familial chilblain lupus (FCL) & TREX1, SAMHDI, STING \\
\hline Systemic lupus erythematosus & TREX1, RNASEH2A-C, ACP5, DNASE1, DNASE1L3, CIQA-C, C4 \\
\hline STING-associated vasculopathy, infantile-onset & STING \\
\hline Singleton-Merten syndrome & $|F| H 1, R I G \mid$ \\
\hline Spondyloenchrondrodysplasia & ACP5 \\
\hline ISG15 deficiency & ISG15 \\
\hline USP18 deficiency & USP18 \\
\hline Chronic atypical neutrophilic dermatosis with lipodystrophy and elevated temperature & PSMB8, PSMB4, PSMA3, PSMB9, POMP \\
\hline X-linked reticulate pigmentary disorder & POLA1 \\
\hline Panarteritis nodosa, childhood-onset & CECR1 \\
\hline
\end{tabular}

Abbreviations: AGS Aicardi-Goutières syndrome; $F C L$ familial chilblain lupus

(https://swissmodel.expasy.org/) to predict the effect of the two mutations on protein structure.

\section{Measuring the expression levels of IFN-stimulated genes in the patient}

Real-time quantitative PCR was performed to measure the expression levels of five IFN-stimulated genes (ISGs) (IFI27, IFI44L, IFIT1, ISG15, RSAD2) in the patient after treatment. The results were compared with the expression levels of these genes in normal controls.

\section{Results}

By analysing the WES results, we found two variants of the TREX1 gene. One was a missense variant (NM 016381; c.C227T; p.Ala76Vla), and the other was a frameshift variant (NM_016381; c.458dupA; p.Gln153Glnfs*3). The two variants were verified using Sanger sequencing (Fig. 4b, c). To verify whether the two variants were de novo or not, the patients' parents were tested using Sanger sequencing. As shown in Fig. $4 \mathrm{~b}$, the father of the proband was a heterozygote of the variant c.C227T, and the mother was a heterozygote of the variant c.458dupA (Fig. 4c). Both mutations were novel. The proband's affected brother carried the same variants as the proband, so the inheritance was in accordance with an autosomal recessive pattern. The damaging score of the missense mutation was 0.83 (damaging score of loss-of-function variant is deemed to be 1) by using VarCards and this mutation was predicted to be probably damaging with a score of 1.000 by using PolyPhen2. According to the SWISS-MODEL prediction, the overall structure of the protein with either missense mutation or frameshift mutation of TREX1 had undergone tremendous changes (Fig. 6), which indicated that these two mutations would affect the structure and function of the protein. Real-time quantitative PCR revealed significantly elevated expression levels of five ISGs (IFI27, IFI44L, IFIT1, ISG15, RSAD2) in the patient than

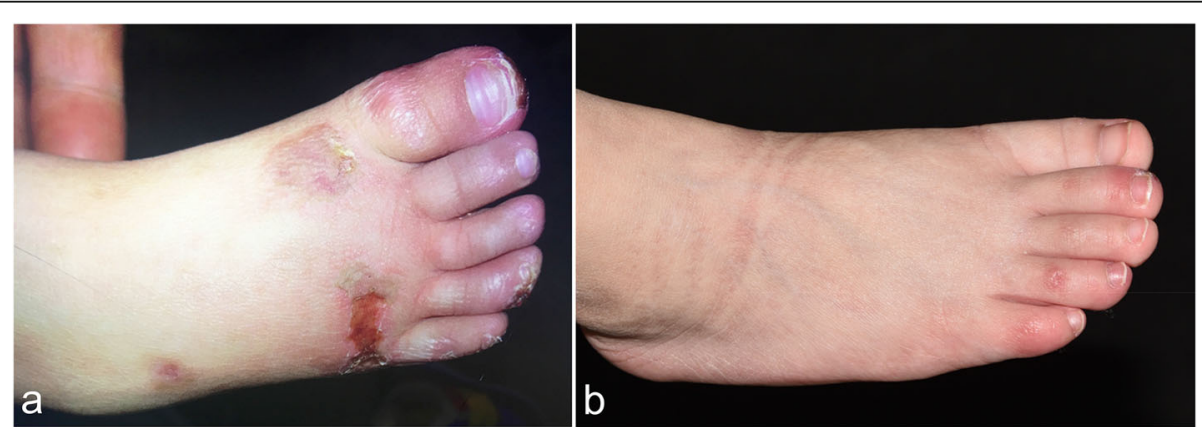

Fig. 1 Clinical manifestations on the foot of the proband. a Chilblain lesions on the toes and the right dorsal feet. b After treatment, the skin lesions were controlled 


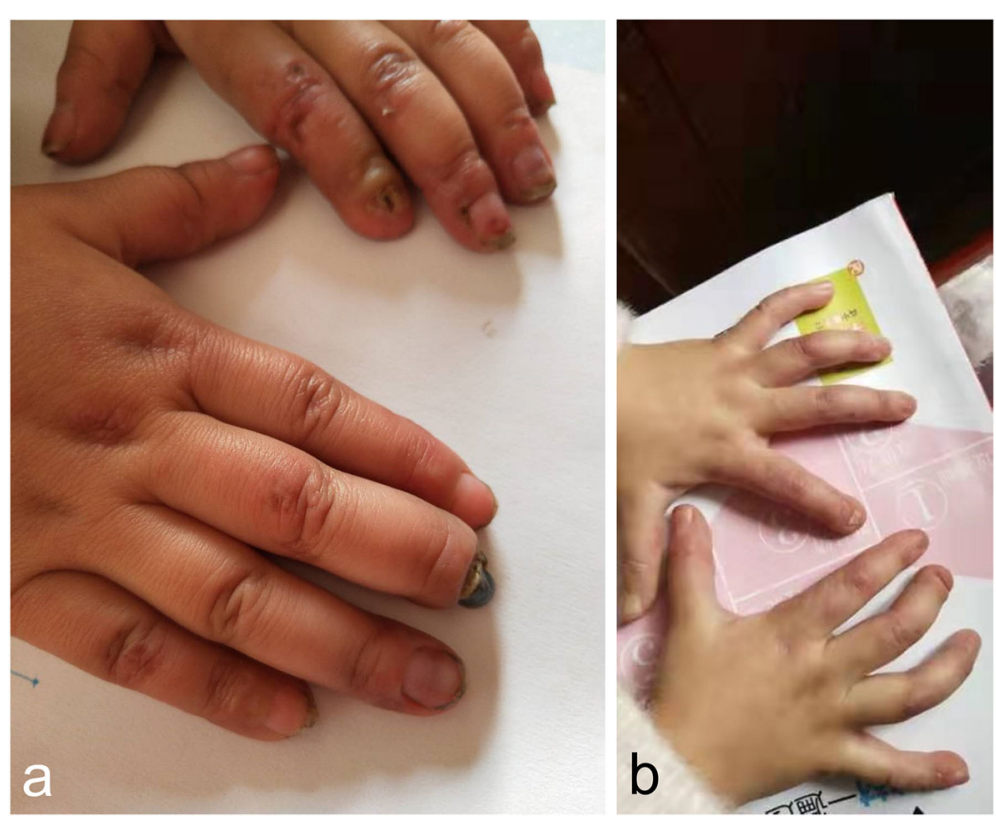

Fig. 2 Clinical manifestations on the hands of the proband. a Chilblain lesions on the fingers. b After treatment, the skin lesions were controlled

in the normal controls (Fig. 7). Accordingly, the patient and her affected brother were diagnosed with FCL.

After the diagnosis was made, the proband was given tofacitinib $2.5 \mathrm{mg}$ bid, which led to marked improvement (Figs. 1b, 2b and 3b). During the following 2 years, the skin lesions and fever could be controlled with tofacitinib alone during the summer and autumn, but got worse during the winter with arthralgia, which could be controlled with tofacitinib $2.5 \mathrm{mg}$ bid and prednisone $5 \mathrm{mg}$ qd. No mild or severe adverse events were observed. She currently lives a normal kindergarten life.

\section{Discussion}

In this study, we found two unreported mutations in TREX1 in a Chinese family. One mutation was a missense mutation (NM_016381; c.C227T; p.Ala76Val), and the other was a frameshift mutation (NM_016381; c.458dupA; p. Gln153Glnfs*3). Previously, researchers had reported on the mechanism of TREX1 causing type I interferonopathies [8]. Diseases associated with TREX1 are shown in Table 2.

The correlation of gene mutations and clinical manifestations of the patients was consistent with the

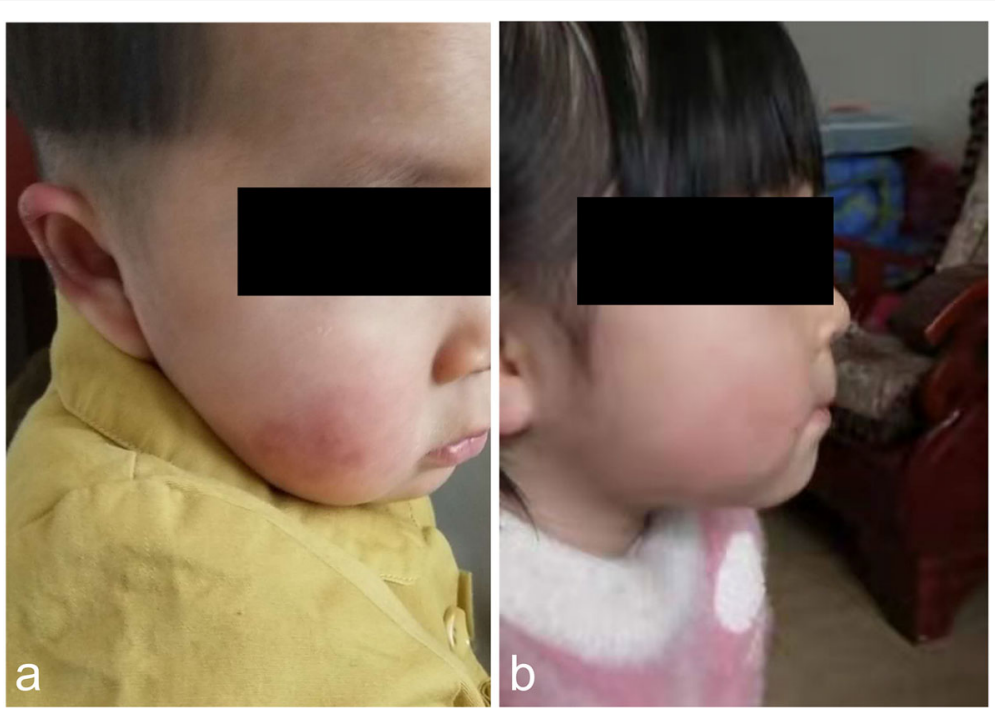

Fig. 3 Clinical manifestations on the face of the proband. a Chilblain lesions on the face. $\mathbf{b}$ After treatment, the skin lesions were controlled 
a

\section{I}

I

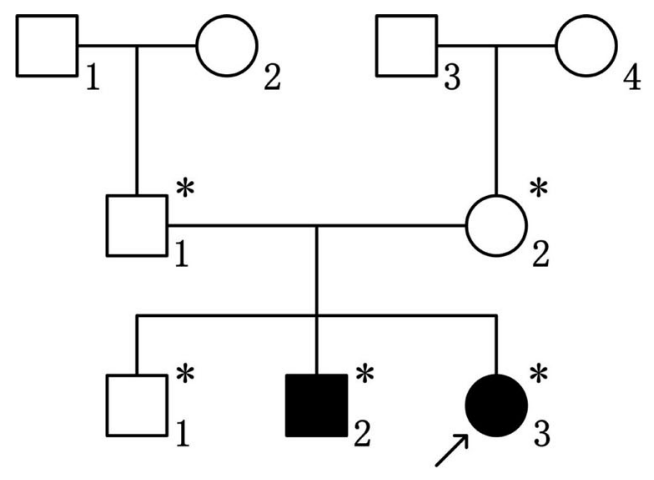

b

II1

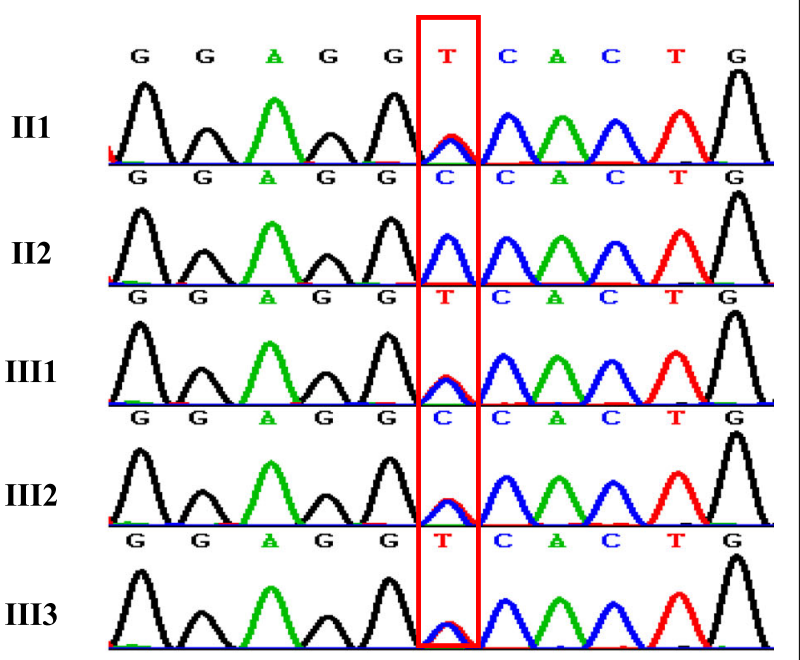

C

II1

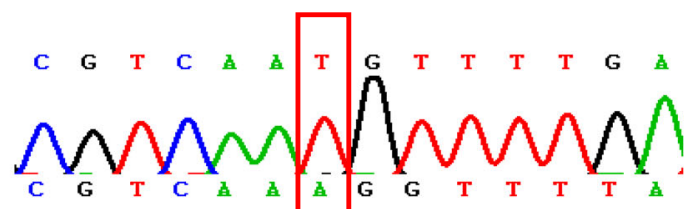

II 2

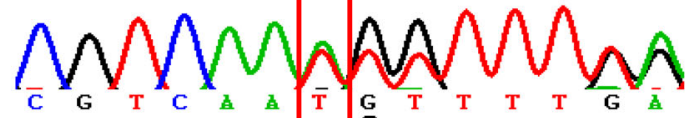

III1

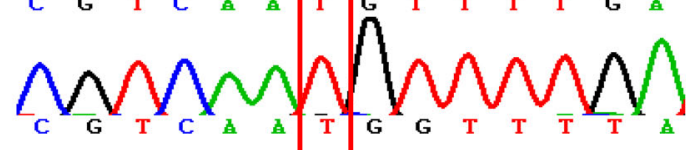

III2

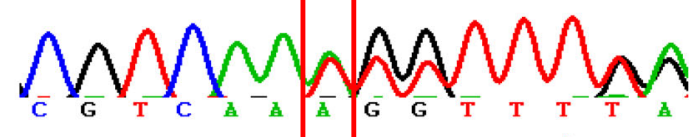

III3

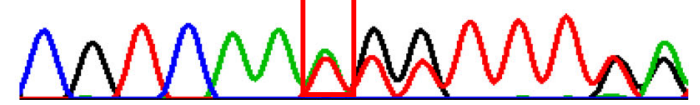

Fig. 4 Pedigree of the family and Sanger sequencing results and identified mutations. a Pedigree of the family with FCL. The arrow indicates the proband, and the asterisks indicate family members who had genetic testing in this study. b, c Sanger sequencing results and identified mutations in pedigree. (b: TREX1 NM_016381; c.C227T; p.Ala76Val. c: TREX1 NM_016381; c.458dupA; p.GIn153fs3)

diagnosis of FCL, a subtype of AGS and one of the type I interferonopathies. The proband and her brother carried the same mutations, but her brother had neurological symptoms in addition to the symptoms on the skin. This was also in consistence with the fact that a deficient activity of TREX1 could affect both the nervous system and the skin, which led to corresponding manifestations in AGS patients.

The proband was given tofacitinib to treat her FCL symptoms and showed improvement. This was consistent with recent studies revealing that JAK or reverse transcriptase inhibitors could benefit patients with type I interferonopathies [9-13]. König et al. reported a family with five members affected by FCL. Two of the members were treated with tofacitinib $5 \mathrm{mg}$ twice daily for 17 days.
On the 14th day of treatment, the IFN signature was significantly suppressed, and the pain and discomfort of the fingers were relieved [11]. The mechanism of the therapeutic effects of tofacitinib in interferonopathies might be that the tofacitinib inhibits the abnormally activated IFN- $\alpha / \beta$ receptor, the JAK/STAT pathway, and the subsequent autoinflammation $[11,14]$. In the CD4 $T$ cells and CD19 B cells from 2 patients with mutation of stimulator of interferon genes (STING) treated with tofacitinib, the phosphorylation of STAT1, STAT2 and STAT3 was blocked [14]. Tofacitinib opened up a new choice of treatment for one of the affected members of the family in this study.

The limitation of this study is that we did not measure the changes in type I IFN in the patient before the 


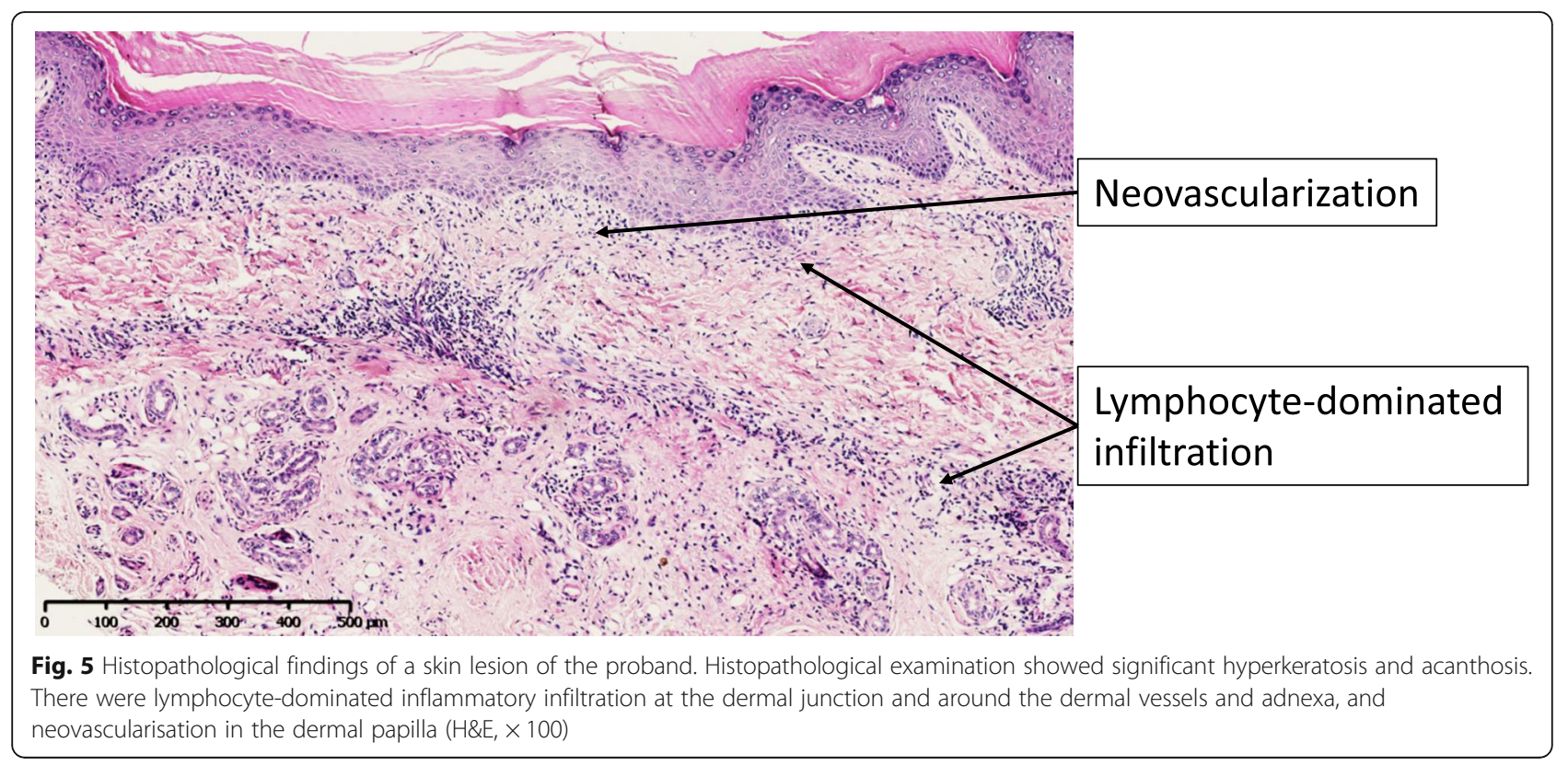

treatment by JAK inhibitor. We sampled the peripheral blood of the patient at his first visit but didn't extract the RNA immediately so that RNA was all gone after it had been stored for too long. Due to the extremely low concentration of type I interferon in blood, it can't be detected directly by using conventional ELISA. Currently, the expression levels of five IFN-stimulated genes (ISGs) (IFI27, IFI44L, IFIT1, ISG15, RSAD2) are generally used to assess the activity of type I interferon signaling pathway [15-17] by real-time quantitative PCR. Here, to provide the supportive evidence for the pathogenicity of the novel compound heterozygous TREX1 mutations, we measured the differences of five ISGs between the patient after treatment and normal controls (Fig. 7). The expression level of the five ISGs of the patient was higher than that of the normal control. Studies have confirmed that the expression of ISGs in patients with type I interferonopathies would have a significant decline before and after treatment by JAK inhibitor [18]. In our study, as shown in Fig. 7, although we only measured the changes of five ISGs in this patient after treatment, we reasonably speculated that the expression level of ISGs in this patient before treatment was also elevated and had be higher than that after treatment. Therefore, this result can be an indirect line of evidence to support the genetic diagnosis of this patient. (a)

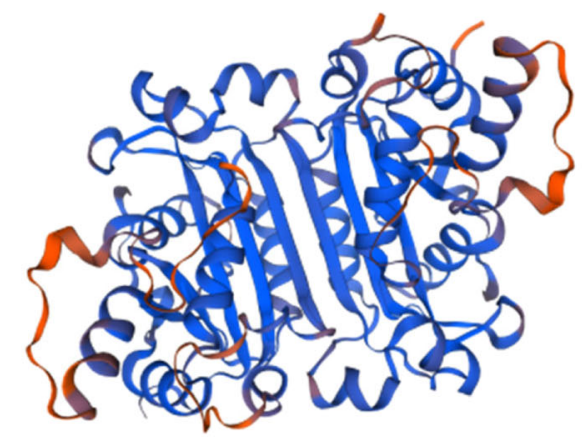

(b)

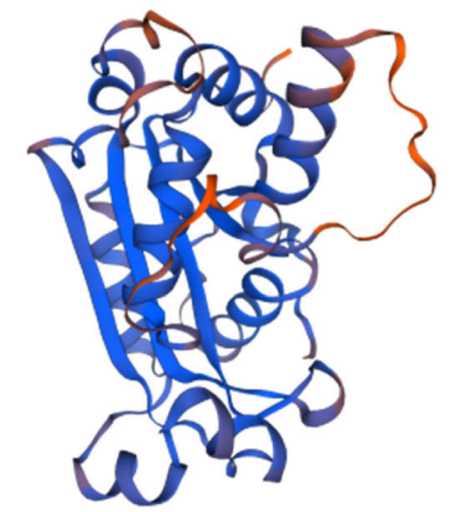

(c)

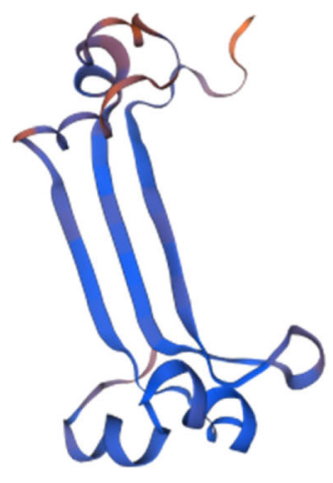

Fig. 6 Effects of the mutations in TREX1 in the patient were simulated by means of SWISS-MODEL. a Predicted normal TREX 1 protein structure. $\mathbf{b}$ Predicted TREX1 protein structure with a specific missense mutation. c Predicted TREX1 protein structure with a specific frameshift mutation 

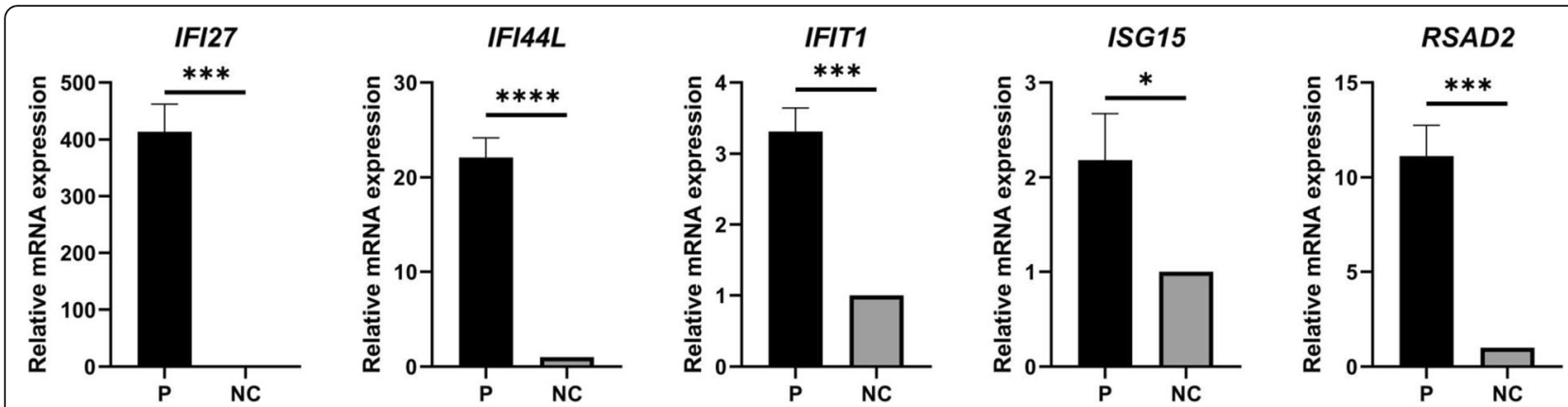

Fig. 7 Targeted IFN-stimulated gene RNA expression in total blood in patient compared with normal control. The ratio of the gene of interest to GAPDH in the normal control was set to 1. Data shown were mean \pm SD of 3 three experiments, and each experiment was performed in duplicate. P: Patient, NC: normal control

This study expanded the mutation spectrum of the TREX1 gene and provided an accurate genetic diagnosis for the affected members of the family. The accuracy of the diagnosis has greatly helped the dermatologists to make decisions on the patient's follow-up treatment, especially for the skin symptoms. In clinical practice, the same or similar symptoms can occur in a variety of skin diseases, which greatly adds to the difficulty in making the correct skin disease diagnosis. The emergence of WES has greatly helped physicians in the diagnosis and

Table 2 Diseases associated with TREX1

\begin{tabular}{|c|c|c|c|}
\hline Disease & Inheritance & $\begin{array}{l}\text { Clinical } \\
\text { manifestation }\end{array}$ & Treatment \\
\hline $\begin{array}{l}\text { Aicardi- } \\
\text { Goutières } \\
\text { syndrome } 1 \\
\text { (AGS1) }\end{array}$ & $\mathrm{AD} / \mathrm{AR}$ & $\begin{array}{l}\text { Progressive } \\
\text { encephalopathy, } \\
\text { developmental } \\
\text { delay, deformity, } \\
\text { foot bun, } \\
\text { frostbite, purpura }\end{array}$ & $\begin{array}{l}\text { NSAIDs, JAK } \\
\text { inhibitor, reverse- } \\
\text { transcriptase } \\
\text { inhibitors }\end{array}$ \\
\hline $\begin{array}{l}\text { Familial } \\
\text { chilblain lupus } \\
\text { (FCL) }\end{array}$ & $\mathrm{AD} / \mathrm{AR}$ & $\begin{array}{l}\text { Painful blue-red } \\
\text { papules or nod- } \\
\text { ules (finger, toes, } \\
\text { nose, cheeks, } \\
\text { ears), skin ulcers } \\
\text { after exposure to } \\
\text { cold and wet }\end{array}$ & $\begin{array}{l}\text { Hydroxychloroquine, } \\
\text { corticosteroids, } \\
\text { cyclophosphamide, } \\
\text { mycophenolate } \\
\text { mofetil, JAK inhibitor }\end{array}$ \\
\hline $\begin{array}{l}\text { Vasculopathy, } \\
\text { retinal, with } \\
\text { cerebral } \\
\text { leukodystrophy }\end{array}$ & $A D$ & $\begin{array}{l}\text { Retinal } \\
\text { vasculopathy, } \\
\text { Raynaud } \\
\text { phenomenon, } \\
\text { CNS degradation }\end{array}$ & $\begin{array}{l}\text { Corticosteroids, NSAI } \\
\text { Ds, clopidogrel, } \\
\text { heparin, } \\
\text { levetiracetam }\end{array}$ \\
\hline $\begin{array}{l}\text { Systemic lupus } \\
\text { erythematosus, } \\
\text { susceptibility to }\end{array}$ & $A D$ & $\begin{array}{l}\text { Fatigue, fever, } \\
\text { arthritis, } \\
\text { mucocutaneous } \\
\text { manifastations, } \\
\text { renal, } \\
\text { hematologic, CNS } \\
\text { involvement and } \\
\text { other systemic } \\
\text { involvement }\end{array}$ & $\begin{array}{l}\text { Hydroxychloroquine, } \\
\text { NSAIDs, } \\
\text { corticosteroids, } \\
\text { methotrexate }\end{array}$ \\
\hline
\end{tabular}

Abbreviations: $A D$ autosomal dominant; $A G S$ Aicardi-Goutières syndrome; $A R$ autosomal recessive; FCL familial chilblain lupus; JAK Janus-kinases; NSAIDs nonsteroidal anti-inflammatory drugs treatment of skin diseases. WES has proved to be a valuable tool in the diagnosis and research of hereditary skin diseases such as interferonopathies and is worthwhile performing.

\section{Conclusions}

In summary, we identified two novel complex heterozygous variants in the TREX1 gene, which may participate in the pathogenesis of the type I interferonopathies observed in patients in this family. Tofacitinib could be an alternative treatment for this disease.

\section{Abbreviations}

AGS: Aicardi-Goutières syndrome; FCL: Familial chilblain lupus; IFN: Interferon; JAK: Janus-kinases; STAT: Signal transducing activator of transcription;

STING: Stimulator of interferon genes; TREX1: Three prime repair exonuclease

1; WES: Whole exome sequencing

\section{Acknowledgements}

We thank Mark Abramovitz, PhD, from Liwen Bianji, Edanz Group China (www.liwenbianji.cn/ac), for editing the English text of a draft of this manuscript.

\section{Authors' contributions}

YL and TW conceptualized and designed the study, coordinated and supervised data collection, and critically reviewed the manuscript for important intellectual content. JS and SZ conducted the experiments and drafted the manuscript. YY, HM and LY collected data and carried out the initial analyses. YL and XZ have made substantial contributions to the conception and substantively revised it. All authors approved the final manuscript as submitted and agree to be accountable for all aspects of the work.

\section{Funding}

This work was supported by grants from the Fundamental Research Funds for the Central Universities [3332018025 to TW], the National Scientific Data Sharing Platform for Population and Health - Clinical Centre [NCMI-ABD02-

201709 to TW], the Beijing Dongcheng District Excellent Talent Support Training project [2019JGM-5 to TW], the Peking Union Medical College Postgraduate Innovation Fund [2019-1002-72 to SYZ], the National Key Research and Development Program of China [2016YFC0905100 to XZ, 2017 YFC1001201 to YL], the National Natural Science Foundation of China (NSFC) [81788101, 81230015 to XZ; 31271345 to YL], the CAMS Initiative for Medical Sciences (CIFMS) [2016-I2M-1-002 to XZ and YL], the National Key Research and Development Program of China Grant No. 2016YFC0901500, and the Centre for Rare Diseases Research, Chinese Academy of Medical Sciences, Beijing, China. 


\section{Availability of data and materials}

The datasets used and/or analysed during the current study are available from the corresponding author on reasonable request.

\section{Ethics approval and consent to participate}

The ethics review board of Chinese Academy of Medical Sciences approved the study. Participants and patients in this study have given written informed consent to be in the study.

\section{Consent for publication}

Participants and patients in this study have given written informed consent to allow the publication of their case details.

\section{Competing interests}

The authors declare that they have no competing interests.

\section{Author details}

'Department of Dermatology, Peking Union Medical College Hospital, Chinese Academy of Medical Sciences and Peking Union Medical College, Beijing 100730, China. ${ }^{2}$ Department of Medical Genetics and National Laboratory of Medical Molecular Biology, Institute of Basic Medical Sciences, Chinese Academy of Medical Sciences and Peking Union Medical College, Beijing 100005, China. ${ }^{3}$ Peking Union Medical College and Chinese Academy of Medical Sciences, Beijing, China.

Received: 16 June 2020 Accepted: 9 December 2020

Published online: 06 January 2021

\section{References}

1. Lee-Kirsch MA. The type I Interferonopathies. Annu Rev Med. 2017;68: 297-315.

2. Rodero MP, Crow YJ. Type I interferon-mediated monogenic autoinflammation: the type I interferonopathies, a conceptual overview. J Exp Med. 2016:213(12):2527-38.

3. Goutieres F. Aicardi-Goutieres syndrome. Brain and Development. 2005; 27(3):201-6.

4. Kisla Ekinci RM, Balci S, Bisgin A, Altintas DU, Yilmaz M. A homozygote TREX1 mutation in two siblings with different phenotypes: chilblains and cerebral vasculitis. Eur J Med Genet. 2017;60(12):690-4.

5. Rice Gl, Rodero MP, Crow YJ. Human disease phenotypes associated with mutations in TREX1. J Clin Immunol. 2015;35(3):235-43.

6. Merchant R, Verma M, Shah A, Kulkarni S, Jalan A. Aicardi-Goutières Syndrome. Indian J Pediatr. 2016:83(8):882-3.

7. Richards A, van den Maagdenberg AM, Jen JC, Kavanagh D, Bertram P, Spitzer D, et al. C-terminal truncations in human 3'-5' DNA exonuclease TREX1 cause autosomal dominant retinal vasculopathy with cerebral leukodystrophy. Nat Genet. 2007:39(9):1068-70.

8. Yan N. Immune diseases associated with TREX1 and STING dysfunction. J Interf Cytokine Res. 2017;37(5):198-206.

9. Sanchez GAM, Reinhardt A, Ramsey S, Wittkowski H, Hashkes PJ, Berkun Y, et al. JAK1/2 inhibition with baricitinib in the treatment of autoinflammatory interferonopathies. J Clin Invest. 2018;128(7):3041-52.

10. Kim H, Brooks KM, Tang CC, Wakim P, Blake M, Brooks SR, et al. Pharmacokinetics, pharmacodynamics, and proposed dosing of the Oral JAK1 and JAK2 inhibitor Baricitinib in pediatric and young adult CANDLE and SAVI patients. Clin Pharmacol Ther. 2018:104(2):364-73.

11. Konig N, Fiehn C, Wolf C, Schuster M, Costa EC, Tungler V, et al. Familial chilblain lupus due to a gain-of-function mutation in STING. Ann Rheum Dis. 2017;76(2):468-72.

12. Stone DL, Ombrello AK, Barron K, Romeo T. Response to JAK inhibition in two children with haploinsufficiency of A20 (HA20) caused by truncating mutations in the ZNF4 domain. Pediatr Rheumatol. 2019;17(Suppl 1):P2092.

13. Yu ZX, Zhong LQ, Song HM, Wang CY, Wang W, Li J, et al. Stimulator of interferon genes-associated vasculopathy with onset in infancy: first case report in China. Zhonghua er ke za zhi. 2018;56(3):179-85.

14. Liu Y, Jesus AA, Marrero B, Yang D, Ramsey SE, GAM S, et al. Activated STING in a vascular and pulmonary syndrome. N Engl J Med. 2014;371(6): 507-18

15. Rice Gl, Del Toro DY, Jenkinson EM, Forte GM, Anderson BH, Ariaudo G, et al. Gain-of-function mutations in IFIH1 cause a spectrum of human disease phenotypes associated with upregulated type I interferon signaling. Nat Genet. 2014:46(5):503-9.

16. Rice Gl, Melki I, Frémond ML, Briggs TA, Rodero MP, Kitabayashi N, et al. Assessment of type I interferon signaling in pediatric inflammatory disease. J Clin Immunol. 2017;37(2):123-32.

17. Sarrabay G, Méchin D, Salhi A, Boursier G, Rittore C, Crow Y, et al. PSMB10, the last immunoproteasome gene missing for PRAAS. J Allergy Clin Immunol. 2020;145(3):1015-7.e6.

18. Meesilpavikkai K, Dik WA, Schrijver B, van Helden-Meeuwsen CG, Versnel MA, van Hagen PM, et al. Efficacy of Baricitinib in the treatment of chilblains associated with Aicardi-Goutieres syndrome, a type I Interferonopathy. Arthritis Rheumatol. 2019;71(5):829-31.

\section{Publisher's Note}

Springer Nature remains neutral with regard to jurisdictional claims in published maps and institutional affiliations.
Ready to submit your research? Choose BMC and benefit from:

- fast, convenient online submission

- thorough peer review by experienced researchers in your field

- rapid publication on acceptance

- support for research data, including large and complex data types

- gold Open Access which fosters wider collaboration and increased citations

- maximum visibility for your research: over $100 \mathrm{M}$ website views per year

At BMC, research is always in progress.

Learn more biomedcentral.com/submissions 